\title{
CNS Spectrums 2018 Peer Reviewers
}

Federica Agosta

Umberto Albert

Cord Benecke

Massimiliano Buoli

Samuel Chamberlain

Foteini Christidi

Volker Coenen

Michael Cummings

Domenico De Berardis

Bernardo Dell'Osso

Massimo Di Giannantonio

Giordano D’Urso

Gianni Faedda

Leonardo Fontenelle

Christos Ganos

Anneke Goudriaan

Giacomo Grassi

Ulrich Hegerl

Sanford Herman

Eric Hollander

Jamie Karagianis

Siegfried Kasper

James Kelleher

Terence Ketter

Gin Malhi

Willem Martens

\author{
Hans-Juergen Moeller \\ Gerald Muench \\ Laura Musetti \\ Glenn Nielsen \\ Oliver Pogarell \\ Bertalan Polner \\ Maurizio Pompili \\ Robert Provine \\ William Reid \\ Zeyad Sahli \\ Ayal Schaffer \\ Kolja Schiltz \\ Ronald Schouten \\ Mary Seeman \\ Susan Shur-Fen Gau \\ Hiroyoshi Takeuchi \\ R.M. Targum \\ Lars Timmermann \\ Antonio Tundo \\ Leandro Valiengo \\ Odile van den Heuvel \\ Gene-Jack Wang \\ Danuta Wasserman \\ Dahua Yu \\ Quan Zhang
}

